\title{
Pier Massimo Prosio, Madame de Staël a Torino, in «Bollettino del C.I.R.V.I.», anno XXIX
}

\section{Marco Stupazzoni}

\section{(2) OpenEdition}

\section{Journals}

\section{Edizione digitale}

URL: http://journals.openedition.org/studifrancesi/7609

DOI: 10.4000/studifrancesi.7609

ISSN: 2427-5856

\section{Editore}

Rosenberg \& Sellier

\section{Edizione cartacea}

Data di pubblicazione: 1 décembre 2009

Paginazione: 642-643

ISSN: 0039-2944

\section{Notizia bibliografica digitale}

Marco Stupazzoni, «Pier Massimo Prosio, Madame de Staël a Torino, in «Bollettino del C.I.R.V.I.», anno xxIX», Studi Francesi [Online], 159 (LIII | III) | 2009, online dal 30 novembre 2015, consultato il 09 janvier 2021. URL: http://journals.openedition.org/studifrancesi/7609 ; DOI: https://doi.org/10.4000/ studifrancesi.7609

Questo documento è stato generato automaticamente il 9 janvier 2021.

\section{(c) $($ ) $(9)$}

Studi Francesi è distribuita con Licenza Creative Commons Attribuzione - Non commerciale - Non opere derivate 4.0 Internazionale. 


\title{
Pier Massimo Prosio, Madame de Staël a Torino, in «Bollettino del C.I.R.V.I.», anno XXIX
}

\author{
Marco Stupazzoni
}

\section{NOTIZIA}

PIER MASSIMO PRosio, Madame de Staël a Torino, in «Bollettino del C.I.R.V.I.», anno xxIX, $\mathrm{n}^{\circ} 58$, fascicolo II, luglio-dicembre 2008, pp. 249-264.

1 In questo studio, l'autore offre una attenta e documentata ricognizione dei luoghi, dei personaggi e degli incontri che riguardarono Mme de Staël in occasione dei suoi due soggiorni a Torino: il primo, dal 20 al 28 dicembre 1804, il secondo, nel suo viaggio di ritorno verso Coppet, dal 17 al 20 giugno 1805, sempre accompagnata da A. W. Schlegel. In quel dicembre del 1804 , Mme de Staël fu accolta con grande calore e cordialità nonostante il clima di diffidenza e di sospetto che circondava la sua persona per i noti dissidi con Napoleone: sono, a questo proposito, preziose le testimonianze fornite dal generale Menou (allora amministratore del Piemonte e marito di un'eccentrica sposa musulmana che immediatamente suscitò l'interesse e la curiosità della scrittrice), e dalle lettere della stessa Staël e dello Schlegel. Da questi brevi squarci epistolari, si evince un sentimento di complessiva indifferenza e di scarso interesse della Staël per la città di Torino da lei considerata, a differenza di Roma, priva di italianità. Se il viaggio del 1804-1805 costituirà, infatti, scrive Prosio, «la fonte di riferimento per Corinne ou l'Italie [...], Torino appare solo di sfuggita» (pp. 254-255) anche se meritano attenzione, come segno di una stima sincera e profonda, i passaggi del libro dedicati a Vittorio Alfieri. Una testimonianza certa (riportata nei Carnets) dell'unico (forse) ricordo diretto di un avvenimento pubblico in cui la scrittrice fu coinvolta in prima persona è quella riguardante la rappresentazione dell'Armida di Haydn al Teatro Imperiale, prima opera della stagione 1804-1805. 
2 In occasione del suo secondo soggiorno torinese (giugno 1805), Mme de Staël ebbe un fitto scambio epistolare con Vincenzo Monti di cui la scrittrice «aveva una alta opinione oltre che una spiccata e dichiarata simpatia» (p. 259). Merita infine di essere ricordata la figura di Diodata Saluzzo che alcuni ipotizzano essere il modello cui la Staël si ispirò per creare il personaggio di Corinne. Riferendosi all'evento della rappresentazione dell'Armida (cui potrebbe aver assistito la Saluzzo), l'autore osserva, in conclusione, che «è suggestivo pensare [...] che a Madame de Staël vedendo la poetessa piemontese nel suo palco venisse in mente di chiamarla Corinne e cioè di farne il primo nucleo della protagonista del suo romanzo» (p. 262). 